\title{
Belief in miracles
}

SIR-With regard to R.J. Berry's question "What to believe about miracles" (Nature 322, 321, 1986), I think it more interesting, and more of a scientific question, to ask how one can understand and explain belief in miracles. Betief in miracles is a widespread and very influential psychological phenomenon, underpinning value systems and cosmologies that have shaped the history of the world. The events called "miracles" may or may not have occurred in the form in which they are described, but their existence as a phenomenon of social fact is very real. This deserves serious investigation.

The main problem with most miracles is the ambiguity of testimony. Often they were reported long after the event, at second-hand; even if the reports are firsthand and attested to "by thousands", it is usually one person who wrote the description. So the data are usually shaky.

There are therefore, a variety of possible hypotheses. One is that the event occurred, and that it was due to divine intervention in some form. A sccond is that the event did not happen at all, that nothing remotely like the event occurred, but that people at a subsequent date constructed mythical events and actions surrounding charismatic figures. This is a virtually universal psychological phenomenon, and indeed there are certain common myths that existed long before their adoption by Christians - the virgin birth, and the death and resurrection of the God, for example, and many religions whose origins are in floodplains have Noah-like heroes in their mythology.

A third hypothesis is that something happened, but there was inadequate information about it, and the ambiguities are resolved in a way that provides both consistency and charisma - such psychological processes are demonstrated for every first-year student in social psychology in laboratory classes.

These explanations do not deny the possibility of miracles, but they do bring into question Berry's distinction between domains of faith and domains of science by asking what parameters of miracles are scientifically interesting. Indeed, Berry`s point about reductionism is an important one, and something that the newer sciences and social sciences have been plagued with. Setting limits to one's science is a way of achieving rigour, by defining what is possible for investigation given the methodological resources available. But such rigour becomes rigor mortis if the limits set are those of one's actual and present methodological constraints, not those of some potential and future, more sophisticated methodology. Developments in psychology have frequently depended on researchers going "off limits" and defining a problem as interesting some time before the methods existed to study it; undoubtedly this is true of all sciences. Berry argues that it is reductionist to say, in effect, that because we cannot study them (given present techniques), miracles are impossible; he is, I would argue, equally reductionist in saying that it is not possible to investigate miracles using scientific measures. It depends which science one applies to the problem.

University of Bath,

Helen Weinreich Haste

School of Humanities and Social Sciences, Claverton Down,

Bath BA2 $7 A Y, U K$

\section{What's in a name?}

SIR-That (novel carbon cluster $\mathrm{C}_{\mathrm{B}_{1}}$ ) which we call Buckminsterfullerene has excited considerable interest while the name we have chosen has stimulated comment ${ }^{2}$. Although many have approved of this name, there have also been criticisms that it is too long (one should consider the IUPAC name), that it is clumsy (which is irrelevant), that nobody has heard of Buckminster Fuller (the name thus has educational value) or that an injustice has been done to almost everyone who has played with symmetrical objects from Plato and Archimedes to Stanley Matthews (the professional footballer).

The molecule we believe we have discovered consists of a sheet network of carbon atoms linked to form a highly resilient hollow sphere. The names of Plato and Archimedes are linked with the regular and semi-regular solids, an association, by the way, which may not be totally justified. The earliest hollow association $I$ have found is in the work of Leonardo da Vinci ${ }^{3}$.

Buckminster Fuller showed that a hollow, light, strong structure could be constructed out of a network of struts using the known principle of Euler that, for closure, 12 pentagonal configurations must be dispersed among the hexagonal ones. The spherical structures such as the Montreal Expo '67 dome, the Epcot Dome and numerous radomes are constructed to take advantage of the lightness, strength (the strains are evenly distributed) and of course the internal cavity, that such a geodesic dome affords. $\mathrm{C}_{600}$ is a geodesic carbon atom network with a very strong inert structure and a large central cavity that can trap other atoms. These three major properties are important for this molecule's behaviour and have direct analogues in the success of Buckminster Fuller's geodesic structures, factors that are not inherent in other names. $C_{(x)}$ Buckminsterfullerene itself is only one member of a set of structures $\left(\mathrm{C}_{14}-\mathrm{C}_{\mathrm{St} 1}\right)$ that appear to be closed and, although they must have 12 pentagonal configurations, do not have to have $t$-icosahedral symmetry. Buckminster Fuller also considered such structures ${ }^{4}$.

\section{School of Chemistry}

and Molecular Sciences,

University of Sussex,

Falmer, Brighton BN1 9QJ, UK

1. Kroto. H.W., Heath, J.R., O'Brien. S.C.. Curl. R.F. \& Smallcy. R.E. Nature 318, 162 (1985)

Stcwart. P.J. Nature 319, 444 (1986)

3. Fra Lucia Pacioli De Divina Proportione Ambrosianit. Milan: Diagrams by Leonardo da Vinci.

Buckminster Fuller. R. Inventions (St Martins Press. New York, 1983)

\section{Spanish universities}

SIR-In two recent issues of Nature (319, 710 and 322, 198; 1986) Juan A. Subirana and Pedro Puigdomenech have pointed out the danger of "inbreeding" in the Spanish universities, as a consequence of the new recruiting system for academic posts. That this danger is becoming fact is demonstrated by the first examinations carried out under the new system.

In most cases, the process of appointment seems to have been a mere formality, the final decision being taken before the examination. Nearly all those obtaining posts were the so-called "official candidates", who were proposed and supported by the university departments before the vacancy was publicly announced. Such candidates began with at least two out of the five votes of the selection committee, those of the members of the department concerned. Other applicants, even those with scientific qualifications superior to those of the official candidates, were often eliminated on the basis of subjective arguments. Work carried out at foreign institutions was undervalued, while some foreign candidates were eliminated by questions such as "What are the idiosyncracies of local students?".

In those circumstances, it is unlikely that many Spanish graduate students and postdoctoral fellows now working in foreign scientific institutions will ever get positions at Spanish institutions. This will not encourage the return of such people to Spain. As a logical consequence, the standard of scientific research in Spain (already much lower than in other Western European countries) will not be raised in the future. This is a serious deficiency in a law that otherwise has many positive features and that was intended to improve the general level of Spanish research. It is a matter of great urgency to reform this system by a new or additional policy.

JAVIER NAVAL

Chimie des Protéines,

Institut de Recherches sur le Cancer. BP 8, 94802 Villejuif, France 